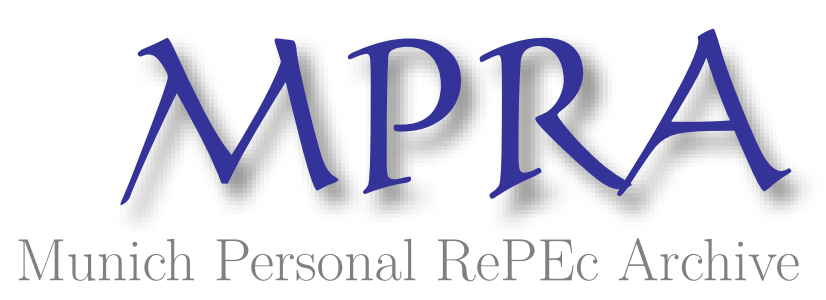

\title{
Assessing the potential of social enterprises through social network analysis: Evidence from Albania
}

Imbert, Enrica and Morone, Piergiuseppe and Bigi, Francesca

Unitelma Sapienza

2016

Online at https://mpra.ub.uni-muenchen.de/78115/

MPRA Paper No. 78115, posted 06 Apr 2017 06:54 UTC 


\title{
Assessing the potential of social enterprises through social network analysis
}

\author{
Evidence from Albania
}

\author{
Enrica Imbert, Piergiuseppe Morone` and Francesca Bigi` \\ - Department of Social and Economic Analysis, Sapienza University of Rome, Italy \\ Piazzale Aldo Moro - 00185 ROMA, Italy (email: enrica.imbert@uniroma1.it) \\ - Department of Law and Economics, Unitelma-Sapienza University of Rome, Italy \\ Viale Regina Elena, 296 - 00161 ROMA, Italy (email: piergiuseppe.morone@unitelma.it | tel. +39 3280431934) \\ - Guri I Zi social enterprise project, Milan, Italy \\ Piazzale Aldo Moro - 00185 ROMA, Italy (email: francesca.bigi@uniroma1.it)
}

\begin{abstract}
Organizations falling within the category of 'social enterprises' are rapidly expanding in developing and transition countries, representing an innovative instrument for poverty reduction and endogenous development. However, economic long-term sustainability remains a major problem. Acquisition of knowledge is then claimed as a key issue for their competiveness and survival in the market. A critical factor for implementing successful knowledge transfer relates to the creation of well-connected networks of relationships. Stable and collaborative contacts among social entrepreneurs also allow more effective coordination, reducing the risk of dispersed and fragmented initiatives. This paper investigates the Albanian social enterprise sector, focusing on their network of relationships (i.e. social enterprises' networks and supporting actors' networks) by means of a social network analysis. Results are based on empirical evidence collected at the firm level from organizations operating in the Tirana and Scutari regions, the heart of the country's economic growth engine. Visual social network investigation along with networks' correlation analysis have showed that Albanian social enterprises are poorly aware of advantages arising from their network of relationships, still showing low entrepreneurial attitudes.
\end{abstract}

Key words: social enterprises, social networks, knowledge flows, foreign aid, sustainable development

JEL codes: L31, O35, D85 


\section{Introduction}

In the last few years the growth of social enterprises has been impressive (see Borzaga and Defourny, 2001; Defourny and Nyssens, 2008). Awareness of its relevance as an effective way of promoting countries' private sector development by ensuring, at the same time, social benefits has been clearly expressed in developed countries (see Austin et al., 2006; Borzaga and Tortia, 2009; Birkhölzer, 2009).

Great interest has also been shown by developing and transition economies. However, despite an increasing diffusion, social businesses are often struggling to survive in these markets.

One of the major problems relates to the lack of knowledge. The European Commission has once again stressed that, "both young and established social entrepreneurs need to build the necessary skills to ensure that their business is well managed and can grow". ${ }^{1}$ Specifically, they need to focus on the acquisition of new knowledge, which is the single most important driver of innovation. ${ }^{2}$

According to the knowledge management literature, innovation must be fully considered as a knowledge-based outcome (Quintane et al., 2011) thus explaining firms' knowledge management efforts as a major source of sustainable competitive advantage (see among others Porter, 1990; Nonaka, 1991; Grant, 1996; Morone and Taylor, 2010). However, enterprises (operating either in high or low-technology industries) cannot acquire all the necessary knowledge in the global market - despite all the progress made by ICT technologies - neither exclusively from internal activities through R\&D or experience-based learning. ${ }^{3}$ Evidence has shown that knowledge has a highly localized nature as it cannot always be transmitted from one place to another through standardized communication tools and is closely bound with the local socio-cultural-institutional context in which it is created (Morone and Taylor, 2010).

In fact, philosopher Polanyi stated "we know more than we can tell" (1966) when he first observed that knowledge cannot be entirely transmitted through structured communication tools. ${ }^{4}$ This seminal statement, which resulted in the development of the 'tacit knowledge' concept, has been further developed by many scholars (see e.g. Cowan et al., 2000; Ancori et al., 2000; Gertler, 2003), becoming a key element in explaining agents' need to enhance the share of knowledge by establishing personal interactions (Nonaka and Takeuchi, 1995).

The diffusion of knowledge through networks of relationships has become a fast growing field of study with contributions from the literature on clusters and regional studies. Even though the literature is mainly focused on high-technology industries, showing why related firms tend to cluster spatially (see Saxenian, 1994; Audretsch and Feldman, 1996; Maillat, 1998; Pinch et al., 2003), it also enables us to better understand why spatial proximity still matters ${ }^{5}$ (Baptista, 2000; Maskell and Malmberg, 1999) in the creation of networks of relationships in an era of globalization (Patel

\footnotetext{
${ }^{1}$ European Commission, 2011. Creating a favourable climate for social enterprises, key stakeholders in the social economy and innovation. COM(2011) 682 final, http://eur-lex.europa.eu.

2 Innovation is commonly viewed as new production technologies and/or product innovation (Oerlemens et al., 1998). Throughout this paper, however, we will refer to its broader definition, which also includes internal organizational improvements (OECD/Eurostat, 2005).

3 "Learning by doing" (Arrow, 1962) and "learning by using" (Rosenberg, 1962) and firm's other activities, including sales and marketing.

${ }^{4}$ Tacit knowledge is generally defined "as knowledge that is either (a) inarticulable, that is, it is impossible to describe in propositional terms, or (b) implicit, that is, articulable but only with some difficulty" (Kimble, 2013: 5). Moreover, it can also be viewed as something that resides in our mind, that we practice in our experience but without consciousness (see Polanyi, 1966; Gertler, 2003).

5 The local dimension of knowledge was predicted by Marshall (1920) whose analysis on the externalities generated by geographical proximity had a strong influence on the later literature focused on localized knowledge spillovers (see e.g. Jaffe et al., 1993; Katz, 1994).
} 
and Pavitt, 1991; Porter, 2000; Pinch et al., 2003) and of new technology diffusion ${ }^{6}$ (HaldinHerrgard, 2000).

In recent years, several empirical studies, conducted at the firm level, have investigated interpersonal informal networks as a means of knowledge diffusion by social network analysis (see among others Giuliani and Bell, 2005; Morone et al., 2006; Giuliani, 2007; Morrison and Rabellotti, 2009). This paper contributes to this field of study focusing on Albanian social enterprises located in the Tirana and Scutari regions - the heart of the country's economic growth engine - attempting to answer three key research questions. ${ }^{7}$

Firstly, whether (and to what extent) Albanian social enterprises are interlinked to each other and to other supporting actors (such as universities, business support organizations, international organizations, etc.). This allowed us to reconstruct two typologies of networks: (1) the social enterprises' networks - comprising inter-enterprise relationships; and (2) the supporting actors' networks - comprising relationships relating to social enterprises with supporting actors. Secondly, whether some social enterprises and supporting actors hold leading positions. Lastly, which type of knowledge, both amongst enterprises and between enterprises and other supporting actors, was exchanged (we distinguish between technical, legal and market related knowledge).

Overall, the proposed investigation aims at assessing the extent to which Albanian social enterprises utilized the two networks to access valuable knowledge. This type of analysis deepens our understanding of the Albanian social enterprise sector, providing us with a particular perspective to analyse its features. The paper is organized as follows: Section 2 is a review of the literature on networks and knowledge diffusion. Section 3 introduces the case study; Section 4 presents the social network analysis method, the survey and the database. Section 5 shows empirical results and, finally, Section 6 concludes and proposes further developments of the study.

\section{Networks and knowledge diffusion}

Firms can be viewed as organizational learning structures where learning is seen "as a purpositive quest to retain and improve competitiveness, productivity, and innovativeness in uncertain technological and market circumstances" (Dodgson, 1993: 378). As already stated, part of their knowledge can only be acquired by 'interacting' with external agents (Lundvall and Johnson, 1994), thus information and knowledge exchanges can also take place between competing firms through informal relationships (von Hippel, 1987; Schrader, 1991; Powell, 1998).

This is the reason for the emergence and diffusion of social networks at the local, regional and national level. Actors establish relationships precisely to acquire resources that cannot be achieved by themselves (Forsman and Solitander, 2003) and the extent of knowledge transfer highly depends on the network structure (Cowan and Jonard, 2004).

As outlined by the above mentioned literature on clusters and by regional studies, spatial proximity might favour knowledge flowing and innovation processes, but an increasing body of evidence has shown that is often not sufficient (see Breschi and Lissoni, 2003; Boschma, 2005; Torre and Rallet, 2005). Moreover, according to Breschi and Lissoni, spatial closeness is no longer satisfactory since it requires a dynamic participation in a network of knowledge exchange created over time. In this context, knowledge can be viewed as a club good, which is not rivalled and non-excludable only for active members of the network (see also Cornes and Sandler, 1996).

\footnotetext{
${ }^{6}$ However, there is an increasing emphasis on non-local relationships and external networks as key success factors in acquiring new knowledge (e.g. Rallet and Torre, 2000; Bathelet et al., 2004).

${ }^{7}$ It should be noted that even though social enterprises have received growing attention in Albania, they are still not defined by the law and mostly operate under the legal umbrella of non-profit organizations (Bonatti et al., 2014). Therefore, it would be more correct to utilize the term 'potential social enterprises' (see e.g. TACSO, 2013), nevertheless, for simplicity's sake we have chosen to refer to the latter as 'social enterprises' throughout the study.
} 
The emphasis given to economic networks as a locus of innovation, demonstrates how established and continuous relationships within networks may increase the effectiveness of an innovation process (e.g. Morone and Taylor, 2010). The economic network approach developed by Hakansson (1989) and Hakansson and Snehota (1995) provides an analytical framework to examine interfirm business relationships, showing that a simple dyadic relationship between two firms cannot be viewed in an isolated context:

\begin{abstract}
"Any business enterprise, no matter how small it is, has to maintain relations with several other actors and some other relationships concur in the development of a certain relationship [...]. Each relationship appears then as embedded in or connected to some other relationships, and its development and functions cannot be properly understood if these connections are disregarded" (Hakansson and Snehota, 1995: 16).
\end{abstract}

The adoption of a 'network perspective', that is a 'relationship view', when studying small enterprises such as those taken under analysis, means precisely to take this wide and complex range of relationships into account, with the aim of understanding their effects on firm performance. Close interpersonal ties remain a crucial condition (e.g. Ingram and Roberts, 2000) as knowledge cannot be shared unless trust between players is created; it is worth noting that social enterprises by their very nature have a natural propensity and ability to develop trusting relationships (Daniele et al., 2009) and, virtually, to build and leverage a network of relationships.

However, one of the main points being discussed in the literature is whether enterprises take advantage of their local network of relationships to acquire specific and more strategic knowledge, or conversely, simply to exchange general information (Dahl and Pedersen, 2004). Finally, whether firms' exchanges tend to be concentrated only between some core firms (e.g. Lissoni, 2001). Our specific research questions fell within this broader area of enquiry, as mentioned in the introduction and as further investigated in the remainder of this paper.

\title{
3. Framing the case study
}

\subsection{Social enterprises and development goals}

Social enterprise began to be formalized in the 1980s, although the academic and political debate on this topic has intensified in the last 20 years (see Defourny and Nyssens, 2010). Even though there is no universally accepted definition of social enterprise, some key elements are commonly recognized. Firstly, it attempts to achieve a social mission, simultaneously pursuing economic and social objectives by providing social services and/or goods to the community or involving disadvantaged individuals in work activities. ${ }^{8}$ A large amount or all of its income comes from its profits, which should be almost entirely reinvested towards achieving its social mission. ${ }^{9}$ Although it produces income through its own business, it can rely on a variety of sources such as development aid and public and private investment. Finally, it is often characterized by a broad range of stakeholders and by a participatory nature ${ }^{10}$ combining waged workers with volunteers.

It should be noted that the term "social enterprise describes the purpose of a business, not its legal form" (BIS, 2011: 1). A wide variety of legal entities, traditional or new specifically designed actually operate as social enterprises, including foundations, associations, cooperatives or commercial limited companies. ${ }^{11} \mathrm{~A}$ vast range of activities may fall under the so-called social mission, including not only the provision of health services or education programmes, but also environmental issues, e.g. sustainable tourism. Moreover, a widely diffused type of social enterprise are the Work Integration Social Enterprises (WISEs) whose main social activity aims at inclusion at work, thus in

\footnotetext{
8 The social purpose characterizing social enterprises' mission should not be confused with corporate social responsibility activities adopted by several for-profit firms.

${ }^{9}$ Generally the threshold to determine whether an organization is a social enterprise is that $50 \%$ of revenues must come from its commercial activities. However, this is a guideline rather than a strict rule.

${ }^{10}$ It is worth noting, however, that that this type of enterprise model is much more diffused in European countries rather than in the US (Kerlin, 2006).

11 "The central driver for social entrepreneurship is the social problem being addressed, and the particular organizational form a social enterprise takes should be a decision based on which format would most effectively mobilize the resources needed to address that problem" (Austin et al., 2006: 2).
} 
society, of vulnerable groups generally excluded from the labour market such as disabled, religious and ethnic minorities and women (see e.g. Davister et al., 2004).

The EMES approach - resulting from the research on social entrepreneurship conducted by the EMES European Research Network since the mid-1990s - has become increasingly influential in EU countries and has been developed in a variety of specific legal and normative frameworks. ${ }^{12}$ This type of approach suggests a definition of social enterprise based on four economic criteria: a continuous activity producing and selling goods and/or services, a high degree of autonomy, a significant level of economic risk and a minimum amount of paid work. ${ }^{13}$

On the other hand, the spreading of social enterprises in the United States has been commonly associated with the diffusion of commercial activities undertaken by non-profits. Embracing the socalled 'social innovation' approach, Americans have also paid considerable attention to the role of individual social entrepreneurs such as Mohammad Yunus (Defourny and Nyssens, 2008; Kerlin, 2006) who has developed and implemented the social business model around the world. ${ }^{14}$ The latter can be viewed as "a subset of social entrepreneurship" (Yunus et al., 2010: 311) and is commonly used together or as an alternative to the term of social enterprise.

With regard to developing and transition countries, the strengths of social enterprises deserve particular consideration, since by their very nature they can be better engaged in complex contexts. ${ }^{15}$ Firstly, they can raise the demand for labour contributing to increased worker ownership (some of them are also employee-owned organizations) and empowerment (see Datta and Gailey, 2012; Haugh and Talwar, 2014). Secondly, they can lead to more sustainable aid projects (reducing reliance on external funds) and increase the economy's supply of goods and services, thus acting as a response to failures and weaknesses of the public sector and the market (see Anheier and Ben-Ner, 2003). Finally, they can play a crucial role in getting out of the informal economy, transforming informal jobs into regulated economic activity, thus increasing domestic tax revenue.

\subsection{The Albanian social enterprise sector}

In recent years, there has been a growing debate on the potential of social enterprises for South East Europe transition economies (e.g. Matei and Matei, 2012; Spear et al., 2013). Their social and economic benefits can have far reaching impact, although their recognition by the local legal systems is often inadequate (see Matei and Sandu, 2011). Albania, indeed, still lacks a specific law on social enterprises, and the different types of organizations currently operating as such mainly refer to the law for non-profit organizations. ${ }^{16}$ Nonetheless, organizations that conceive themselves

\footnotetext{
${ }^{12}$ Given this strong heterogeneity, social enterprise still does not exist as a statistical category even though several surveys have been carried out at national levels.

${ }^{13}$ However, these criteria must not be intended as a set of conditions. EMES has also identified five social criteria: an explicit aim to benefit the community; an initiative launched by a group of citizens; a decision-making power not based on capital ownership; a participatory nature, which involves various parties affected by the activity; a limited profit distribution.

${ }^{14}$ According to Yunus, Social business is "a social oriented self-supporting economic activity whose surplus is reinvested in the activity or preserved as a precautionary measure and the owners must remain committed to never take any dividend beyond the return of the original amount they invested" (Yunus, 2010: xix). The initial capital may come from bilateral and multilateral donators (creation of social business funds), foundations and corporate social responsibility firms budgets.

${ }^{15}$ Indeed, "in many cases, a social entrepreneur can still meet with some degree of success, while pursuing an opportunity, despite an inhospitable context. In fact, social entrepreneurs may choose to pursue opportunities to address social change not despite of, but because of, an inhospitable context. Thus, social entrepreneurs may respond in fundamentally different ways to adverse contextual conditions than their commercial counterparts" (Austin et al., 2006: 9).

${ }^{16}$ Law No. 8788/2001 amended with law No. 92/201378. Accordance with Article 36 of law No.8788/2001 A non-profit organization has the right to exercise economic activity for the realization of the purpose and object of its activity. A nonprofit organization may exercise economic activity without having to create a separate subject for this reason, provided that the activity is in conformity with the purposes of the non-profit organization, has been declared as one of the sources of income, and provided that the activity is not the primary purpose of the activity of the organization. Finally, any profits must be reinvested for the achievement of social objectives for which the economic activity has born. Article 40 , which is currently under revision, exempts non-profit organizations from paying revenue taxes.
} 
as social enterprises are spreading all across the country. The dynamism of this sector is further demonstrated by several annual conferences held in Tirana on this topic and by the creation of the Albanian Forum on Social Enterprises (ASE).

Lately, policymakers have also shown increased interest in the role social enterprises can play in addressing some of the country's most pressing issues - above all, the magnitude of the informal sector, which negatively affects public debt and wide-spread unemployment, especially among youths and women (EC, 2014). In 2011 the government of Albania set up the Agency for Social Business Promotion, as part of the government's strategy for job creation and social inclusion, which works closely with the Social Business Movement of Albania launched in 2012 by Yunus Social Business. ${ }^{17}$ Also, significant progress has been made in producing a more coherent legal framework since the Ministry of Social Welfare and Youth, in conjunction with the Ministry of Economic Development, Trade and Entrepreneurship, elaborated on a draft law on social enterprises.

In addition to associations and foundations, the draft law recognizes other legal forms including cooperatives, limited liability companies and joint stock companies. As stressed during the national conference on 'The role of Civil Society Organizations in developing Social entrepreneurship in Albania', the main features of the draft law are the non-distribution of profits among members (no wages should exceed $20 \%$ of the organization's turnover) and the use of participatory governance models beyond the legal form adopted by the social enterprise.

Moreover, as for fiscal regime, the draft law also foresees a possibility for the exemption from taxes on profits and the reduction of VAT on the products and services provided by social enterprises. This represents a major step since the government has so far not planned out a sound economic policy to support social entrepreneurship.

In April 2014, the Balkan countries' social organizations jointly signed the Belgrade Declaration, a statement committing them to implement the creation and development of social enterprises. This is a key achievement for governments such as that of Albania to approve the draft bill that will allow greater enhancement and further expansion of the Albanian social entrepreneurship throughout the country more quickly.

Within this dynamic and rapidly changing environment, we shall now try to assess the present status of Albanian social enterprises' social network of relationships and its future potential development, by means of a case study conducted in the Tirana and Scutari regions.

\section{Methodology}

\subsection{Social network analysis tools}

Relational networks can be viewed as a favourable space to exchange knowledge but, in order to analyse them, appropriate tools must be put in place. Social network analysis (SNA) provides an explicit formal method to map and measure these kinds of informal flows, making the once invisible set of relationships visible ${ }^{18}$ (Cross et al., 2003). A social network consists of any group of people, institutions or organizations embedded in multiple kinds of relationships. ${ }^{19}$

'Nodes' are the actors under analysis ${ }^{20}$ and 'ties' the range of relationships connecting actors (Wasserman and Faust, 1994). By means of graph theory, nodes are represented by points

\footnotetext{
17 Of the 34 social enterprises surveyed in our study, six received financial and technical support by Yunus Social Business Albania.

${ }_{18}^{18}$ Although is seen more as a specific perspective of analysis by many scholars.

${ }^{19}$ The basic assumption underlying a social network analysis, originally applied to sociology, anthropology, psychology and subsequently to other social sciences such as economics, assumes that relationships among actors have a high influence on their behaviour (Knoke and Yang, 2008).

${ }^{20}$ For instance: individuals, informal or formal organizations as enterprises, institutions, etc.
} 
(vertex) and ties by a set of lines (edges). ${ }^{21}$ This easily allows the visualization of the agents' relationships collected using specifically designed questionnaires. To this purpose, collected data need to be arranged in an adjacency matrix - i.e. a means of representing which nodes of a graph are adjacent to which other nodes. In substance, information collected in an adjacency matrix allows the reconstruction of the overall network structure, the calculation of its architectural properties and identification, among other things, of influential actors - i.e. those actors occupying a central position in the social network. While explaining the reasons for a network analysis applied to non-governmental organizations (NGOs), Dershem et al. (2011: 7) emphasized the aim of improving it because "when networks of people or organizations are better connected they are more cohesive, productive and resilient. Also, the denser the network, the easier it is for information to spread and coordination to occur". This is an important point since it could also allow the reduction of the risk of dispersed and too similar initiatives, which represent one of the greatest weaknesses of social enterprises (see Rykaszewski et al., 2013).

In performing SNA, we used a set of standard measures and indices to study the distinctiveness and structural properties of networks, of which the main ones are summarized in Table 1.

Table 1. Social network indexes

\begin{tabular}{l|l}
\hline Index & Characteristics \\
\hline Density & Ratio of existing ties to all possible connections. \\
\hline Inclusiveness & $\begin{array}{l}\text { The number of connected points expressed as a proportion of } \\
\text { the total number of points. }\end{array}$ \\
\hline Average degree & $\begin{array}{l}\text { The sum of connections (edges) associated with each actor } \\
\text { (vertex) in the social network. }\end{array}$ \\
\hline Clustering coefficient & $\begin{array}{l}\text { A measure of the degree to which actors (vertexes) in a } \\
\text { network tend to cluster together. }\end{array}$ \\
\hline Network centralization & $\begin{array}{l}\text { A network index that measures the degree of dispersion of all } \\
\text { node centrality scores in a network from the maximum } \\
\text { centrality score obtained in the network. The centrality } \\
\text { measures the number of connections (edges) incident upon an } \\
\text { actor (vertex). }\end{array}$ \\
\hline Cut-point & $\begin{array}{l}\text { A pivotal point of articulations between the elements that make } \\
\text { up a component. It indicates some type of local centrality, and } \\
\text { the absence of cut-points implies that communication and } \\
\text { exchanges among the members of a component are not } \\
\text { dependent upon any one member. }\end{array}$ \\
\hline
\end{tabular}

Source: Scott (1991); Wasserman and Faust (1994).

\subsection{Survey and data collection}

In order to identify our population of interest we conducted a preliminary survey in the field. The assistance provided by the most important actors supporting Albanian social enterprises, such as the EU funded project 'Technical Assistance for Civil Society Organizations' (TACSO) Albania, the Albania Social Enterprises (ASE) Forum, IPSIA-ACLI Albania and the Yunus Social Business Albania, allowed us to identify the various types of organizations involved in this kind of business and working in the Tirana and Scutari regions.

Networks' data were gathered through semi-structured interviews and questionnaires. The questionnaire was divided into three sections to collect relational data and actors' attributes. ${ }^{22}$ The first introductory section aimed to collect general data on the legal forms used to conduct social enterprise by the different organizations operating in the Tirana and Scutari regions and on their management, with a clear distinction between the social and economic activities carried out. The second section collected information on the typologies of networks of relationships to which Albanian social enterprises refer, while the third section explored in more detail the nature of such

\footnotetext{
${ }^{21}$ If the lines show arrowheads, then these latter indicate the direction of the relationship. These kinds of graphs are known as directed graphs or digraphs.

${ }^{22}$ The questionnaire is available from the authors on request.
} 
relationships. As mentioned in the introduction, we consider two typologies of networks: (a) social enterprises' networks and (b) supporting actors' networks (see Figure 1). For each of these two networks' typology we looked at: (1) generic interactions (which allowed the construction of the network of interactions); (2) general communication interactions (which allowed the construction of the communications network); (3) knowledge based interactions (which allowed the construction of the knowledge networks). Specifically, we focused on three main categories of knowledge diffusion: technical knowledge (production-system related knowledge that can directly affect the productivity of social enterprises), legal knowledge (knowledge about the regulatory framework within which social enterprises operate in Albania), and market knowledge (knowledge about markets and consumers' preferences).

The social enterprises' networks have been constructed using a roster-recall method augmented through the 'snowball' method, as survey participants were asked to identify other social enterprises not listed in the initial roster of actors. In the end, we obtained a final list of 34 social enterprises. ${ }^{23}$ Supporting actors' networks, on the other hand, have been constructed using a preordered category-list of supporting actors identified through expert interviews augmented through the 'snowball' method. In particular, social enterprises were asked from which categories of actors they were receiving support in their entrepreneurial activity, also providing the name(s) of the specific supporting actors. ${ }^{24}$ Therefore, we obtained a final list of 34 social enterprises and a list of 9 categories of supporting actors.

All networks data have been gathered in Excel matrices and imported into the software Ucinet 6 (Borgatti et al., 2002), which allowed us to visualize and analyse enterprises' relationships through graphs.

A pilot version of the questionnaire was tested by three organizations to check the understanding of the wording of the questions and relevance to the Albanian context. After a few changes, the final questionnaire was administered by face-to-face interviews in three subsequent rounds (in June 2013, January and July 2014).

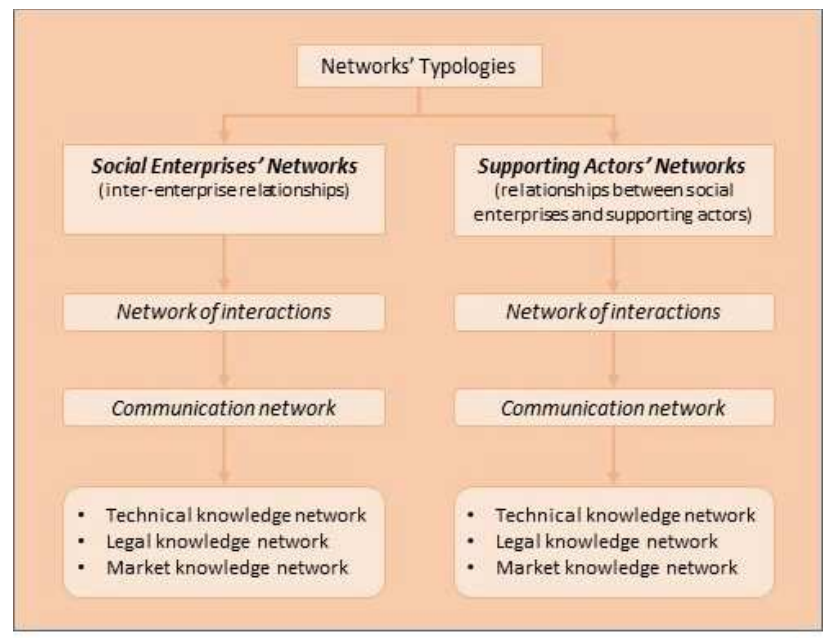

Figure 1. Overview of networks' typologies

Source: Authors' own elaboration.

${ }^{23}$ An initial list of 50 social enterprises was later increased to 66 organizations through the snowball method. Subsequently, 32 organizations were removed from the list, as we were able to verify with their local managers that they were traditional NGOs and not social enterprises. This is a key issue since, to be considered a social enterprise, organizations need to carry out an entrepreneurial economic activity although aimed at pursuing social wellbeing rather than maximizing profits as commercial enterprises. A key challenge of our analysis, compared to similar previous investigations (e.g. TACSO, 2013), was precisely to make an extra effort to retain only those organizations that can genuinely be considered social enterprises, excluding from the social network analysis those organizations that, through our in-depth preliminary analysis, were shown to be regular NGOs and not real social enterprises.

${ }^{24}$ It is worth noting that supporting actors were not interviewed directly. Hence, only outbound relationships (corresponding to social enterprises in-degree) were detected. 


\section{Results}

\subsection{Sample features}

When asked about their economic activity mission, $40 \%$ of respondents surveyed declared that they provided social services, $39 \%$ declared that they employed disadvantaged individuals, and $21 \%$ were devoted to both missions. Most of the economic activities shown in Figure 2 are directed at the local or domestic market, and about one third to the European and international market.

With respect to economic sustainability, the majority of respondents reported that they derived half their revenue from philanthropic donations and half from their economic activities; over a third of respondents claimed to still depend mostly on donations. This finding is consistent with previous research (TACSO, 2013) and is partly due to the fact that most of these organizations are still at an early stage of development but, clearly, also to structural problems.

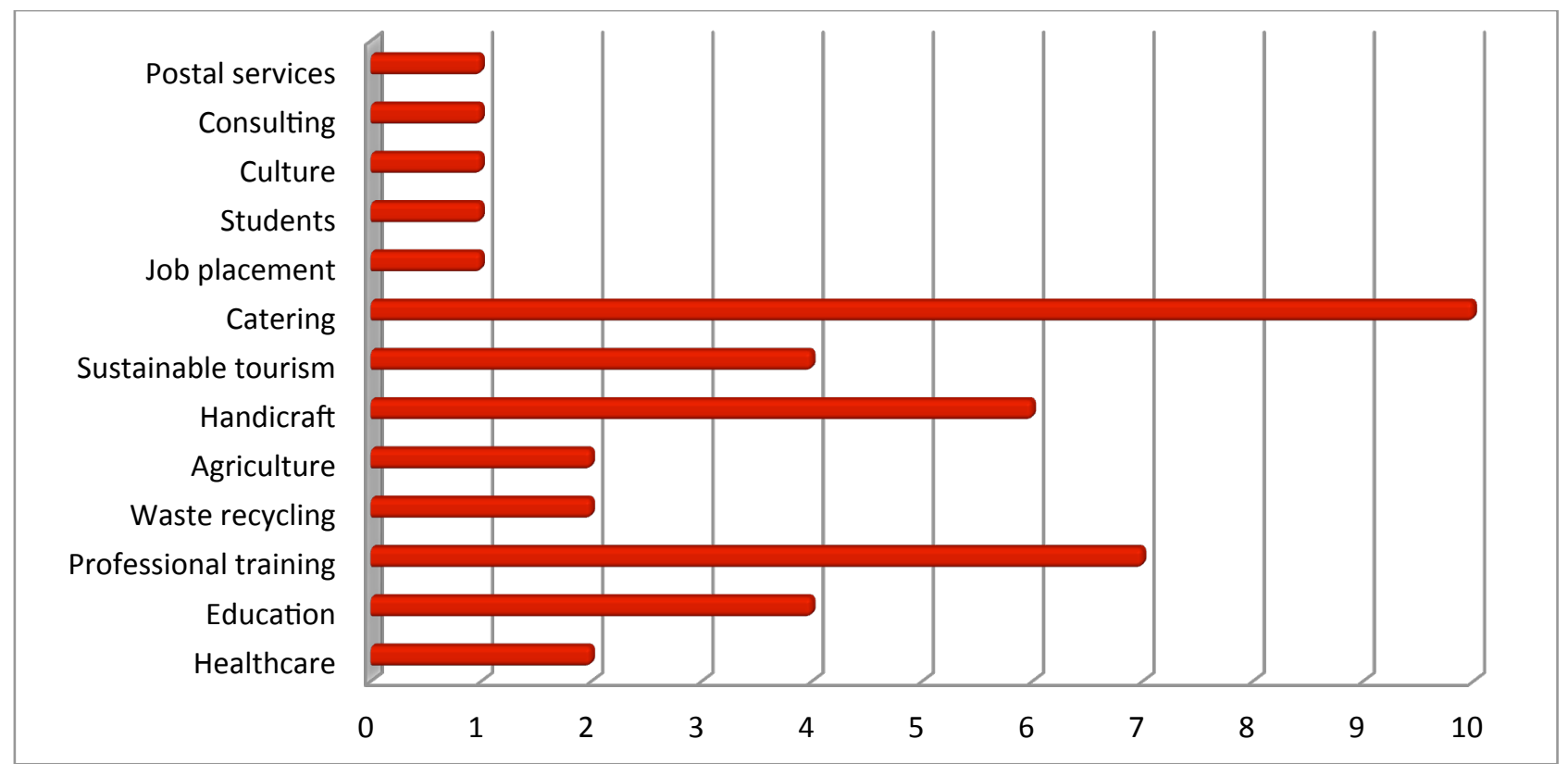

Figure 2. Economic activities of social enterprises operating in the Tirana and Scutari regions

Source: Authors' elaboration on survey data

Almost all respondents agreed on a number of critical issues faced by their organizations. First, economic sustainability registered the highest frequency of response. ${ }^{25}$ In particular, concerns have been raised about the difficulty that many organizations have in finding a commercial outlet for their activities. The Albanian economy is still significantly below the EU average, and consumers' purchasing power was severely hit by the global economic crisis preventing families from buying goods and services (see Instat Albania, 2013; Dávalos et al., 2015). Secondly, knowledge and skills gaps have been stressed, in particular knowledge and skills related to marketing and market research. Finally, social enterprises reported about problems related to the weakness and uncertainty of the Albanian regulatory framework over social enterprises; above all, that they do not obtain recognition of the tax-exempt status from the government.

\subsection{Analysis of social enterprises' networks}

The first network (Figure 3a) is the network of interactions and includes all relationships between social enterprises regardless of their quality and content. The 34 social enterprises are linked by 294 non-directional ties (Table 2). The density of the network is rather high and equal to 0.52 , which means that there are more than half of all possible ties (which in an ordinary undirected nonreflexive graph, such as in our case, is $l=\frac{n(n-1)}{2}$, where $n$ is the number of nodes and $l$ are all

${ }^{25}$ Only two companies have not mentioned economic sustainability as a major problem. 
possible ties). No enterprise is disconnected from the rest of the network. This is an important finding, as any random part of social enterprises, though not directly connected, share an opportunity for interacting through alternative pathways. Additionally, the overall network's clustering coefficient and centralization are quite high (Table 2, Row 1), showing that Albanian social enterprises tend to cluster especially in areas where the presence of key organizations facilitates networking.

\section{Table 2. Social enterprises' networks indexes}

\begin{tabular}{|l|c|c|c|c|c|}
\hline Network & $\begin{array}{c}\text { Number of } \\
\text { relations }\end{array}$ & Density & Inclusiveness & $\begin{array}{c}\text { Clustering } \\
\text { coefficient }\end{array}$ & Centralization \\
\hline Network of interactions & 294 & $52 \%$ & $100 \%$ & $45 \%$ & $33 \%$ \\
\hline Communication network & 170 & $30 \%$ & $97 \%$ & $35 \%$ & $19 \%$ \\
\hline Technical knowledge network & 144 & $25 \%$ & $91 \%$ & $29 \%$ & $18 \%$ \\
\hline Legal knowledge network & 44 & $7 \%$ & $53 \%$ & $10 \%$ & $21 \%$ \\
\hline Market knowledge network & 52 & $8 \%$ & $71 \%$ & $14 \%$ & $24 \%$ \\
\hline
\end{tabular}

Source: UCINET6 on authors' database

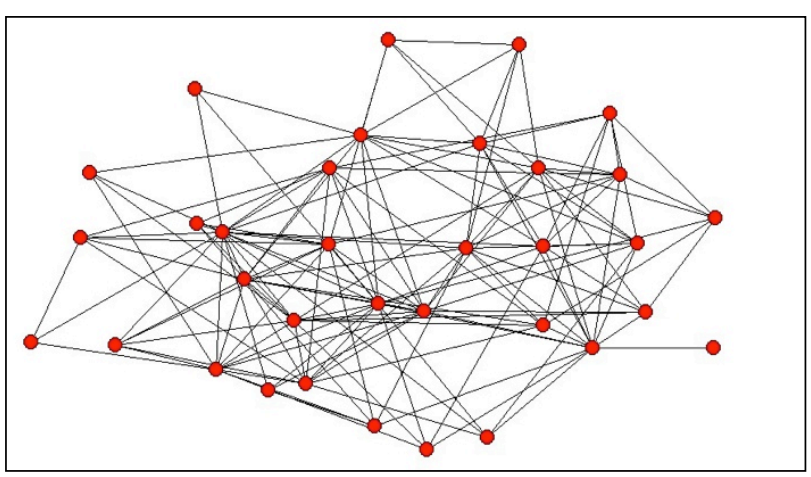

Figure 3a: Network of interactions

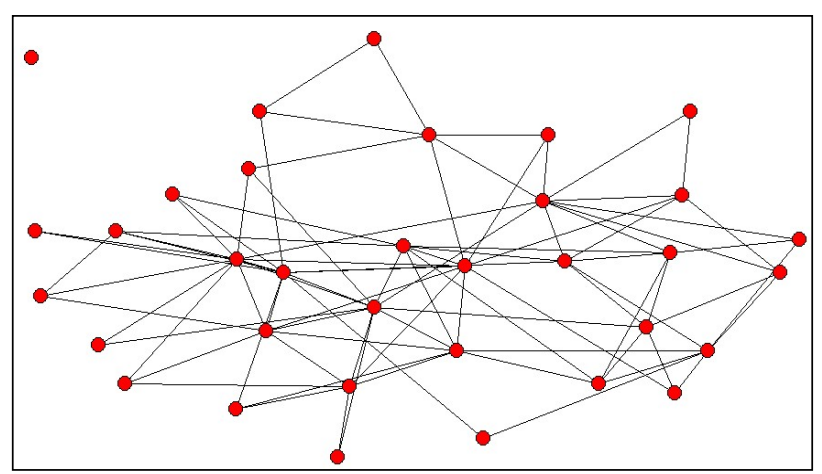

Figure 3b: Communications network

Source: UCINET 6 on authors' database

The selection of communication relationships enabled us to reconstruct the communications network (Figure 3b), formed by a lower number of non-directional ties: 170 as opposed to 294. It results in a less cohesive graph, showing a drop in the system density from $52 \%$ to $30 \%$. This suggests that a fewer number of Albanian social enterprises are actually engaged in information and knowledge exchanges. The overall network's clustering coefficient and centralization also decreased, reaching $35 \%$ and $19 \%$ respectively. However, inclusiveness is still very high, there is just one isolated node meaning that also in this case almost all enterprises can reach each other.

The next step was to divide the communications network into the three sub-categories mentioned above. Figures $4 \mathrm{a}, 4 \mathrm{~b}$ and $4 \mathrm{c}$ display these three sub-networks where red circles represent nodes, blue diamonds represent cut-points and shapes dimension depends on nodes degree. When moving into these three networks concerning specific types of knowledge, relationships among enterprises decrease more drastically, especially for the legal and market ones. The technical knowledge network shows quite a positive result because, although the number of relationships decreases if compared to the communications network, the inclusiveness rate is still high. However, the overall graph's clustering coefficient reduced to a lower level (Table 2, Row 3) while centralization remained almost unchanged. 
In contrast, in legal and market knowledge networks there are several isolated actors, respectively 15 and 10 . Hence, they necessarily show a lower inclusiveness rate and the overall clustering coefficient of the graphs show a decreasing pattern (10\% and $14 \%$ respectively). On the other hand, the centralization of both networks has increased (21\% and $24 \%$ respectively). In fact, the legal and market knowledge networks show a different structure characterized by the presence of single actors occupying a prominent position in the graphs, suggesting that networks' activities are largely concentrated around these organizations.

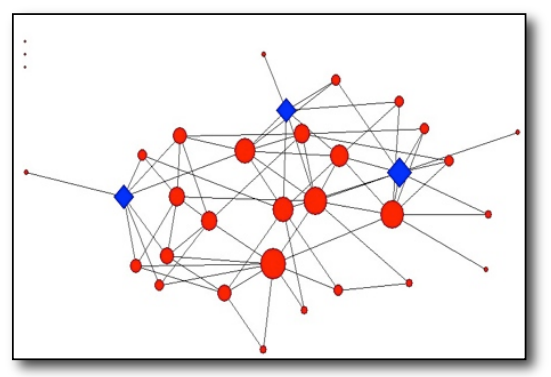

Figure 4a. Technical knowledge network

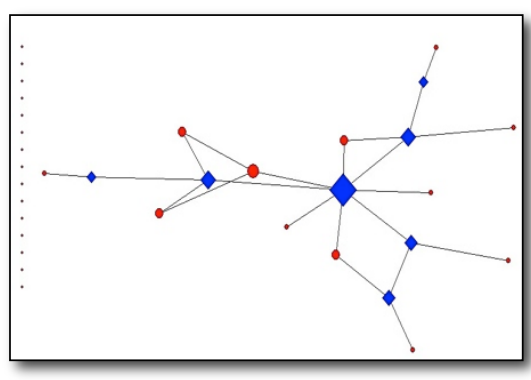

Figure 4b. Legal knowledge network

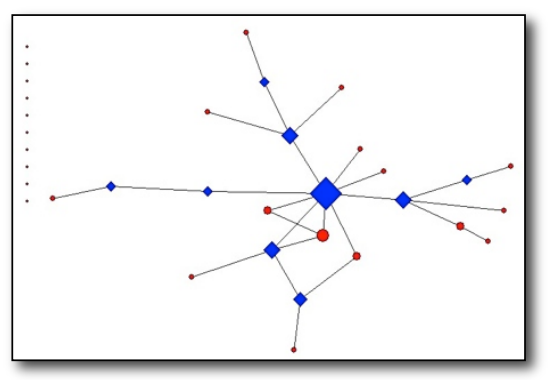

Figure 4c.

Market knowledge network

Key: red circles represent nodes; blue diamonds represent cut-points; shapes dimension depends on nodes degree.

Source: UCINET 6 on authors' database.

Another important finding emerging from a visual inspection is that in all three knowledge networks the non-isolated nodes all become connected into a single component. Although these are weakly connected components, it still shows the existence of a path from any node to any other, ignoring isolated nodes. In this respect, the absence of sub-groups (i.e. multiple components) shows that the cohesiveness of the network is a uniform property of the social network, across all three relational content specifications.

Following this line of reasoning, we extend our analysis by looking at the cut-points represented in the above-studied networks by blue diamonds (Figures $4 a, 4 b$ and $4 c$ ). The importance of cutpoints lies in their ability to connect (and, conversely, to disconnect) two or more components of a social network. Hence, these nodes may act as brokers among groups, building bridges between sub-groups that would otherwise be cut-off and split into unconnected components or actors. When considering the flow of any material or immaterial attribute through a social network, a cut-point actually represents a bottleneck through which the attribute must flow to reach a portion of the social network. These nodes are, therefore, quite important in the overall diffusion process, as they directly control a portion of the network that could be isolated from the rest of the network if the cutpoint is unable (or unwilling) to facilitate the flow.

As is quite clearly illustrated in Figures $4 \mathrm{a}, 4 \mathrm{~b}$ and $4 \mathrm{c}$, the technical knowledge network is characterized by the presence of only three cut-points, which are also quite peripheral in the overall structure of the network. This is indeed an important finding, since it suggests that technical knowledge flows in this network are not significantly dependent on any particular member. The presence of alternative paths of communication among actors suggests that the architectural structure of this system is both flexible and unstratified.

Conversely, both the legal knowledge network and the market knowledge network are characterized by the presence of several cut-points, which occupy central positions in the two architectures. This finding suggests a further limitation of these two networks, where the flow of knowledge is not only limited to a very small portion of actors, but is also dependent on a few key nodes whose absence would determine a collapse of the systems. 


\subsection{Analysis of supporting actors' networks}

Beyond inter-firm relationships, a range of other actors can play a key role in providing enterprises with the knowledge, skills and competencies needed to improve their market reach. As mentioned earlier, relationships with the main players supporting Albanian social enterprises, together with the preliminary survey in the field, enabled us to identify nine categories of crucial actors from which information and knowledge can be potentially transmitted in the specific context of the Albanian social enterprises, namely international institutions, international NGOs, Albanian NGOs, forum of social enterprises, business support organizations, universities, local authorities, traditional enterprises and non-Albanian social enterprises. Thus, our supporting actors' networks include the 34 Albanian social enterprises and 9 categories of external actors in which the latter send and enterprises receive information and knowledge (see Gorgoni and Pietrobelli, 2010).

In the network of interactions (see Table 3), the 34 social enterprises are linked with supporting actors by 222 directional ties and no enterprise is isolated. The overall network centralization is high $(65 \%)$ with local authorities, international institutions, international NGOs and forum of social enterprises playing a leading role. In particular, the majority of respondents declared to have some kind of connection with European Institutions, the Italian Development Cooperation and the Albanian National Forum on Social Enterprise.

\section{Table 3. Supporting actors' networks indexes}

\begin{tabular}{|l|c|c|c|c|}
\hline Network & $\begin{array}{c}\text { Number of } \\
\text { relations }\end{array}$ & Density & Inclusiveness & Centralization \\
\hline Network of interactions & 222 & $24 \%$ & $100 \%$ & $65 \%$ \\
\hline Communication network & 157 & $17 \%$ & $98 \%$ & $54 \%$ \\
\hline Technical knowledge network & 114 & $15 \%$ & $93 \%$ & $49 \%$ \\
\hline Legal knowledge network & 93 & $10 \%$ & $91 \%$ & $45 \%$ \\
\hline Market knowledge network & 78 & $8 \%$ & $95 \%$ & $41 \%$ \\
\hline
\end{tabular}

Source: UCINET6 on authors' database

In the communications network we have a smaller number of directional relationships (157 compared to 222), but still a high inclusiveness as only one enterprise is isolated from the network. International institutions and NGOs still play an important role, while local authorities play a relatively minor role. Moreover, universities become the latest player for number of relationships ${ }^{26}$.

\footnotetext{
${ }^{26}$ Network of interactions and communications network graphs are not displayed but are available from authors on request.
} 


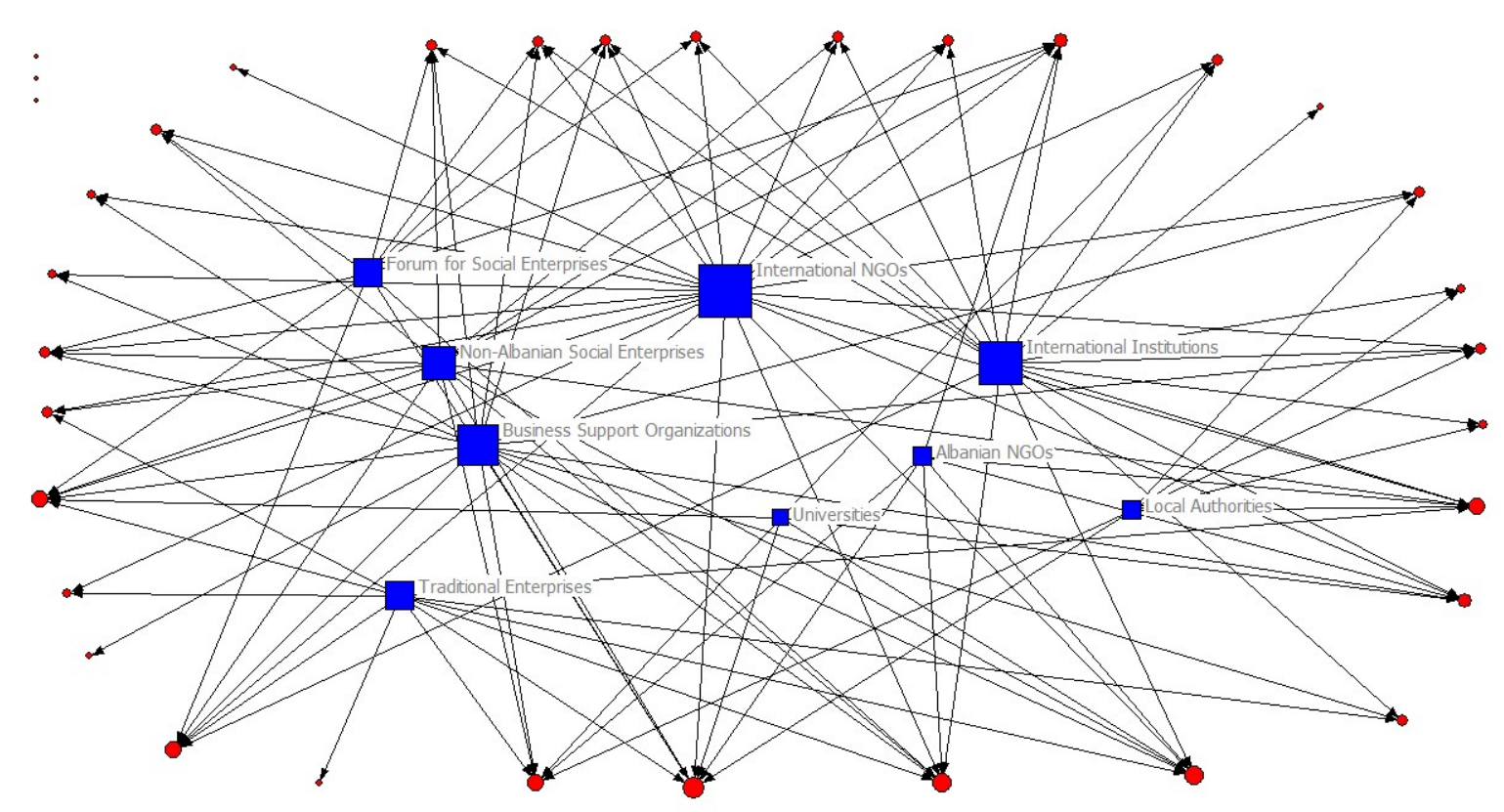

Figure 5a. Technical knowledge network

Key: Red circles represent social enterprises; blue squares represent supporting actors; shapes dimension depends on nodes degree.

Source: UCINET 6 on authors' database.

When moving into the technical knowledge network (Figure 5a) directional relationships decrease to 114 ties; however, also in this case inclusiveness is still quite high as only three enterprises are isolated. It is worth noting that beyond international institutions and international NGOs, a central role is now played by business support organizations, particularly by Yunus Social Business, which has proven to be a major reference point for a large number of Albanian social enterprises. In the legal network (Figure $5 \mathrm{~b}$ ) we have a lower number of directional ties (Table 3 ) and slightly lower inclusiveness. Universities (placed between isolated nodes) are completely excluded from transfers of this type of knowledge, while the forum for social enterprises, specifically the Albanian Forum on Social Enterprises, has a key role.

Despite more than $70 \%$ of respondents pointing to difficulties in acquiring knowledge and skills related to marketing and market research, the market knowledge (Figure $5 \mathrm{c}$ ) contains the lowest number of ties, although showing a higher inclusiveness compared to the technical and the legal ones. Looking at this network, we can, however, observe that business support organizations have a very high degree together with traditional enterprises that, for the first time, gained an important role. 


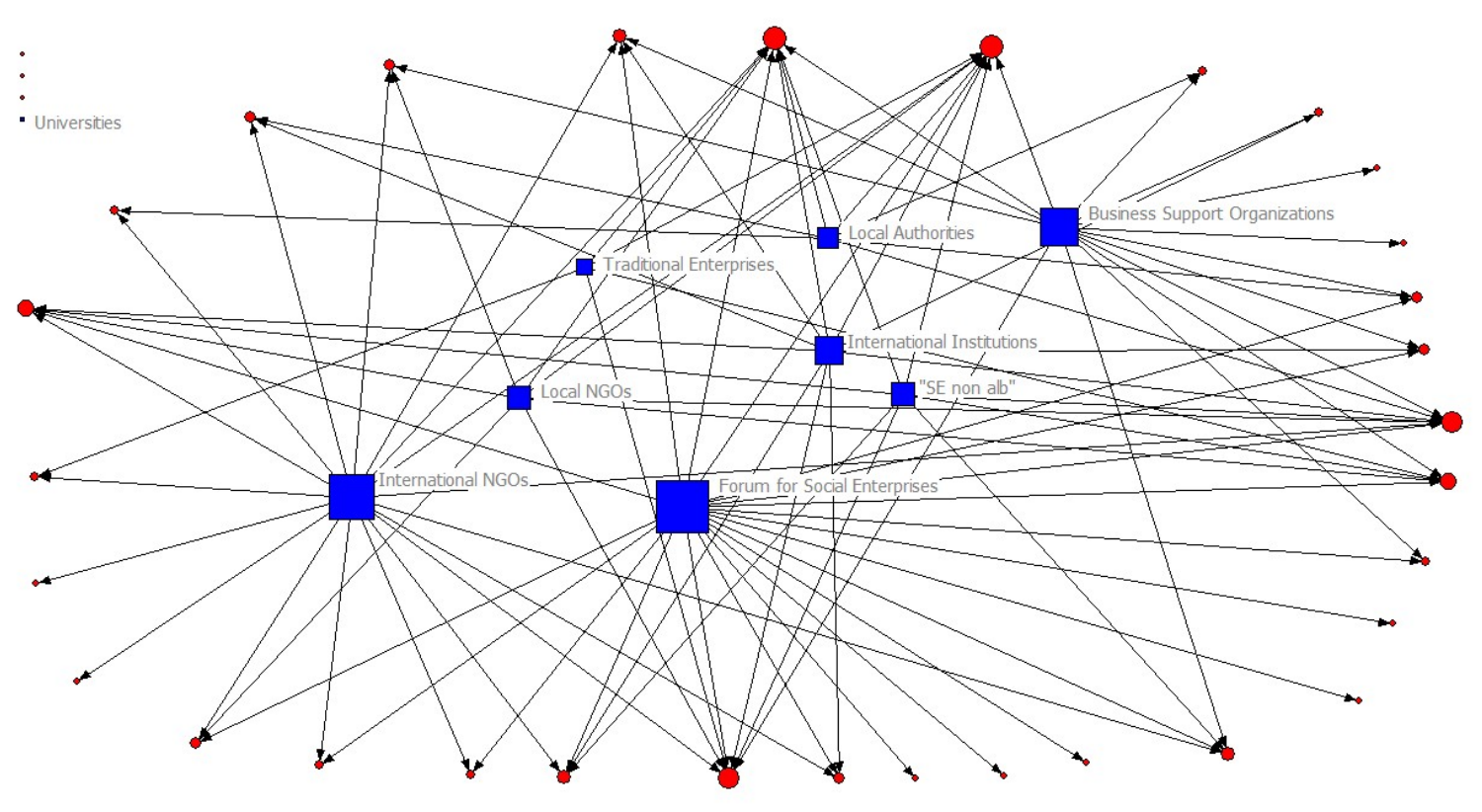

Figure 5b. Legal knowledge network

Key: Red circles represent social enterprises; blue squares represent supporting actors; shapes dimension depends on nodes degree.

Source: UCINET 6 on authors' database.

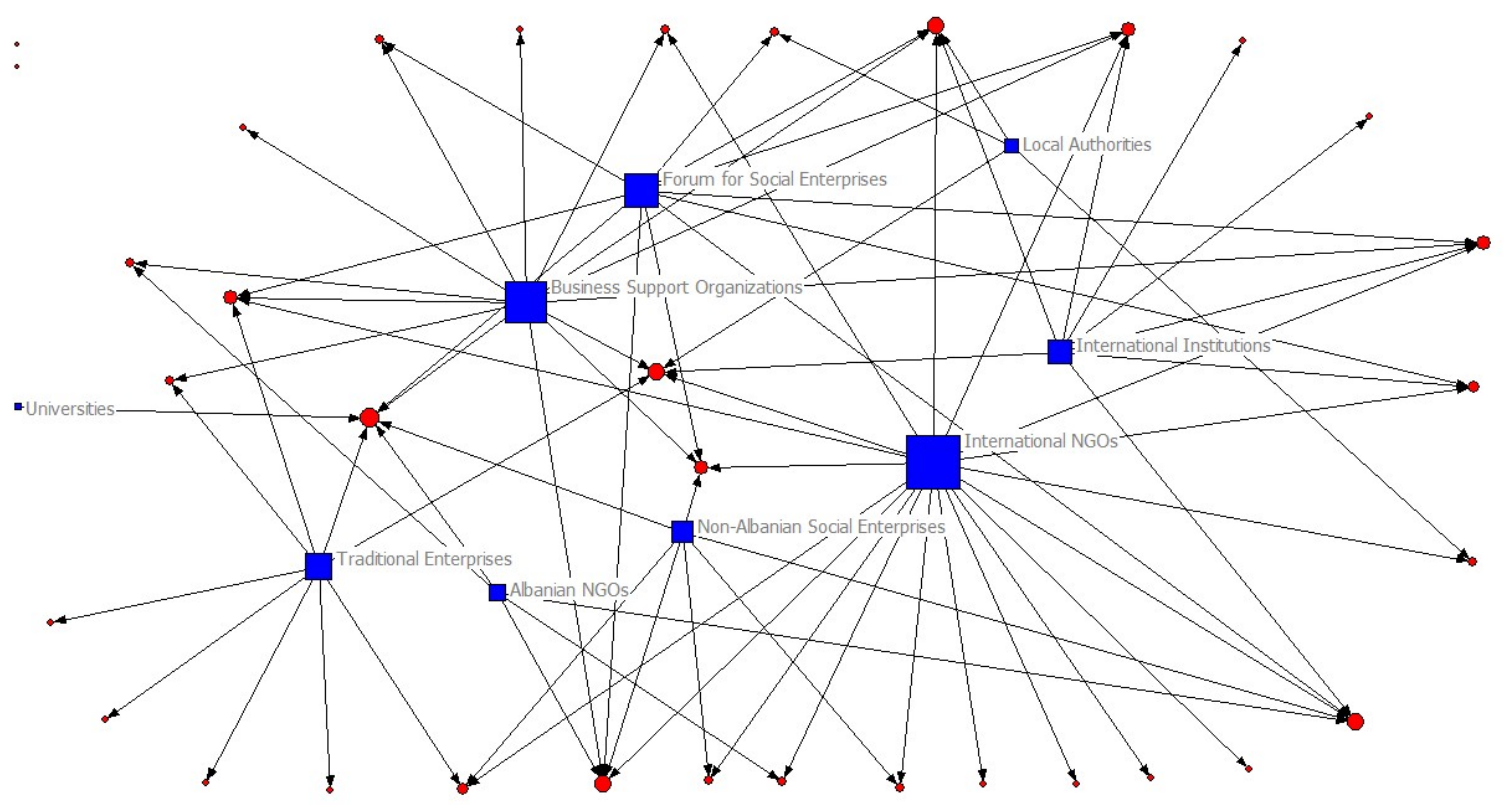

Figure 5c. Market knowledge network

Key: Red circles represent social enterprises; blue squares represent supporting actors; shapes dimension depends on nodes degree.

Source: UCINET 6 on authors' database.

\subsection{Networks correlation analysis}

Since we have information about different knowledge exchanges among the same sets of actors (i.e. social enterprises), it is of considerable interest to assess whether the probability of one type of knowledge exchange is related to the probability of another. For instance, if organizations exchange one type of knowledge, this may create a sense of trust, making the probability of exchanging other types of knowledge more likely. That is, we might hypothesize that the three 
knowledge network matrices would be correlated with each other - pairs that engage in one type of knowledge exchange are more likely to engage in the others. Alternatively, it might well be the case that the three types of knowledge flows have nothing to do with one another (no correlation), or even that two types of knowledge flows are correlated and the third one is not. Hence, we conclude our social network analysis testing within each of our two typologies of networks (social enterprises' networks and supporting actors' networks) the extent to which knowledge networks are correlated.

Specifically, in order to compute correlations, we use the "Quadratic Assignment Procedure" (QAP) by UCINET 6, which takes place in two steps. In the first step, it computes Pearson's correlation coefficient and other measures, such as simple matching, Jaccard ${ }^{27}$ and Hamming distance ${ }^{28}$, between corresponding cells of the two data matrices. In the second step, it randomly permutes rows and columns (synchronously) of one matrix and recalculates the correlation coefficients. This second step is performed hundreds of times in order to find the proportion of times that a random measure is larger than or equal to the observed measure calculated in step one. A low proportion $(<0.05)$ implies a robust relationship between the matrices that is fairy improbable to succeed by chance.

As shown in Table 4, social enterprises' knowledge networks display quite high correlation values for all considered types of knowledge. In particular, market and legal networks obtained the highest value, suggesting that these types of knowledge tend to flow together, while technical knowledge seems to flow through more independent pathways. Additionally, when considering the above analysed features that emerged from the structure analysis of the market and legal networks, we can state that these two knowledge flows, beyond being strongly correlated, are also restricted to a hard core of social enterprises.

\section{Table 4. Correlation between knowledge flows in social enterprises' networks}

Technical-Market knowledge
\begin{tabular}{|l|c|c|c|c|c|c|c|c|c||c|c|c|c|c|}
\hline Correlation Indexes & Value & Signif & Avg & SD & Correlation Indexes & Value & Signif & Avg & SD & Correlation Indexes & Value & Signif & Avg & SD \\
\hline Pearson Correlation & 0.511 & 0.000 & 0.001 & 0.045 & Pearson Correlation & 0.458 & 0.000 & 0.001 & 0.044 & Pearson Correlation & 0.785 & 0.000 & 0.000 & 0.044 \\
\hline Simple Matching & 0.909 & 0.000 & 0.837 & 0.018 & Simple Matching & 0.902 & 0.000 & 0.842 & 0.018 & Simple Matching & 0.982 & 0.000 & 0.918 & 0.019 \\
\hline Jaccard Coefficient & 0.315 & 0.000 & 0.036 & 0.019 & Jaccard Coefficient & 0.262 & 0.000 & 0.032 & 0.018 & Jaccard Coefficient & 0.655 & 0.000 & 0.022 & 0.023 \\
\hline Hamming Distance & 102 & 0.000 & 182 & 7 & Hamming Distance & 110 & 0.000 & 176 & 7 & Hamming Distance & 20 & 0.000 & 91 & 4 \\
\hline
\end{tabular}

Source: UCINET 6 on authors' database.

When considering supporting actors' knowledge networks (see Table 5), we also found quite high correlation values, a finding that is consistent amongst all types of knowledge. Taking into account the low density values of these networks (see Table 3 ), in this case we can assume again the existence of a hard core of enterprises gaining all considered types of knowledge from supporting actors while a large number of enterprises reveal to be not actively involved in these networks.

\section{Table 5. Correlation between knowledge flows in supporting actors' networks}

Technical-Market knowledge $\quad$ Technical-Legal knowledge Market-Legal knowledge

\begin{tabular}{|l|c|c|c|c|l|c|c|c|c||l|l|l|l|l|l|l|l|l|}
\hline Correlation Indexes & Value & Signif & Avg & SD & Correlation Indexes & Value & Signif & Avg & SD & Correlation Indexes & Value & Signif & Avg & SD \\
\hline Pearson Correlation & 0.684 & 0.000 & 0.000 & 0.049 & Pearson Correlation & 0.650 & 0.000 & 0.000 & 0.053 & Pearson Correlation & 0.678 & 0.000 & -0.000 & 0.047 \\
\hline Simple Matching & 0.967 & 0.000 & 0.899 & 0.019 & Simple Matching & 0.962 & 0.000 & 0.892 & 0.019 & Simple Matching & 0.971 & 0.000 & 0.909 & 0.019 \\
\hline Jaccard Coefficient & 0.524 & 0.000 & 0.027 & 0.025 & Jaccard Coefficient & 0.500 & 0.000 & 0.030 & 0.027 & Jaccard Coefficient & 0.527 & 0.000 & 0.024 & 0.024 \\
\hline Hamming Distance & 60 & 0.000 & 182 & 9 & Hamming Distance & 69 & 0.000 & 195 & 10 & Hamming Distance & 53 & 0.000 & 162 & 8 \\
\hline
\end{tabular}

Source: UCINET 6 on authors' database.

\footnotetext{
${ }^{27}$ The Jaccard coefficient computes the positive matches between matrices.

${ }^{28}$ The Hamming distance is a measure of the dissimilarity between networks since it computes the number of values that differ from one matrix to another (Hanneman and Riddle, 2005). The closer its value is to zero, the greater is the similarity between matrices.
} 
As a final step of our investigation we attempt to correlate knowledge flows across the two typologies of networks: i.e. we want to investigate whether being able to receive knowledge inflows in one typology of network is positively, negatively or not correlated with the ability to receive knowledge inflows in the other typology of network.

However, we cannot use QAP as the two matrices are different in size (recall that the supporting actors' networks include 34 social enterprises plus 9 categories of external actors ${ }^{29}$ ). Therefore, we reverted to a different methodology. Specifically, we computed for each social enterprise the indegree for each typology of network (i.e. social enterprises' networks and supporting actors' networks) and for each type of knowledge (i.e. technical, legal and market related). Then we compute actor-by-actor correlations indexes comparing in-degree values across networks' typologies, keeping invariant the knowledge type. Hence, we had 34 correlation values for each knowledge type network. The aim of this correlation exercise is to assess whether the two reticular sources of knowledge (social enterprises' networks and supporting actors' networks) are considered by enterprises as being substitutes or complements - i.e. under the substitute option we would expect correlation to be low as social enterprises either access technical- legal- and/or market-related knowledge through linking with other peer social enterprises or through establishing network relationships with other supporting actors; the opposite would be true under the complementarity option.

We generally found low correlation values, which seems to support the hypothesis that Albanian social enterprises take advantage from either of the two typologies of networks, that is they consider the two sources of knowledge as substitutes. In order to corroborate this finding we proceeded by computing the in-degree mean value of both typologies of networks for each of the types of knowledge considered in our analysis. Thus, we labelled each actor with an $\mathrm{H}$ if they showed an in-degree above the mean value and with an $L$ otherwise. Subsequently, for each type of knowledge flow we classified actors in four groups: HH; HL; LH; LL. As an exemplification, an actor classified as $\mathrm{HH}$ in the market knowledge network would display above-average in-degree values both in the social enterprises' networks and supporting actors' networks. Hence, HH actors are those showing above-average knowledge gains in both typologies of networks - i.e. for those actors, the two network typologies are perceived as complementary sources of knowledge flows. The opposite will be true for those actors classified as $\mathrm{HL}$ or $\mathrm{LH}$. In this case, in fact, the two typologies of networks are rather considered as substitute sources of knowledge. Finally, note that actors classified as LL are those showing a below-average ability to gain knowledge in both network's typologies.

In Figure 6 we report a summary figure showing the number of actors falling in each group for the three types of knowledge flows.

Social Enterprises Networks

\begin{tabular}{|c|c|c|}
\hline & $\begin{array}{l}\text { Technical Knowledge: } 9 \\
\text { Legal Knowledge: } 6 \\
\text { Market Knowledge: } 10\end{array}$ & $\begin{array}{l}\text { Technical Knowledge: } 6 \\
\text { Legal Knowledge: } 6 \\
\text { Market Knowledge: } 3\end{array}$ \\
\hline & $\begin{array}{l}\text { Technical Knowledge: } 11 \\
\text { Legal Knowledge: } 13 \\
\text { Market Knowledge: } 14\end{array}$ & $\begin{array}{l}\text { Technical Knowledge: } 8 \\
\text { Legal Knowledge: } 9 \\
\text { Market Knowledge: } 7\end{array}$ \\
\hline
\end{tabular}

Figure 6. Knowledge flows comparison across the two networks typologies

Source: Authors' own elaboration

${ }^{29}$ See footnote 24 . 
As it shows, we found that less than $20 \%$ of social enterprises take advantage from both typologies of networks (this figure even drops to $10 \%$ for market knowledge). Furthermore, about one third of the enterprises benefit neither from one network nor from the other, falling in the LL group. The remaining social enterprises, about $50 \%$, show a propensity towards $\mathrm{LH}$ or $\mathrm{HL}$, confirming that a large part of the studied social enterprises consider the two networks' typologies as substitute sources of knowledge (regardless of the type of knowledge) rather than complementary.

\section{Conclusions}

The social network analysis presented in this study allowed us to reconstruct the web of informal relationships of Albanian social enterprises, as well as the relational content of such connections, thus allowing us to investigate this emerging sector from a particular perspective. Specifically, we focused on social enterprises' acquisition of (various types of) knowledge through two possible reticular sources, i.e. social enterprises' networks and supporting actors' networks.

Overall, we found that social enterprises are expanding widely throughout Albania, although they are still facing many barriers. Together with the shortage of investment capital and an unsuitable legal framework, the major constraints reported by respondents are a lack of expertise and limited knowledge. Most of the enterprises' managers declared to come from non-profit organizations, and only a few of them are well trained in business management.

With respect to social enterprises' networks, our survey dataset showed that more than half of the potential relationships are exploited by social enterprises and that none of these actors is completely isolated from the others. This is a very important result, meaning that both international and local actors have done well and that these enterprises have collaborated to some extent.

Conversely, when moving to networks concerned with specific exchanges of knowledge (technical, legal and market related) the density of relationships decreases significantly and the overall cluster capacity between organizations drops considerably.

Specifically, we found major negative results when considering legal and market knowledge networks, arising from some concomitance of elements in their constitution, the first being the large number of disconnected agents and the high level of centralization, together with the presence of cut-points located in strategic positions of the networks. Consequently, the imbalance across organizations has risen considerably and the whole networks' structure appears to be very fragile.

With respect to supporting actors' networks, international NGOs are ranked top in all types of networks. On the other hand, relationships between social enterprises and business support services, international social enterprises and traditional enterprises - which may contribute more effectively to the development of appropriate business plans and to the overall management strategies' effectiveness - are insufficiently exploited. This is despite the fact that we observed an encouraging increasing role of business support organizations in the technical and market networks. Other important findings are the extremely limited role of Universities, albeit in line with other studies (e.g. Gorgoni and Pietrobelli, 2010) that outlined the minor role played by such institutions in sectors still performing low levels of R\&D, and the key role played by the Albanian Forum on Social Enterprises for acquiring legal knowledge.

When comparing our two networks' typologies, we observe a similar trend as density decreases when we move from interaction networks to specific knowledge networks, especially with regard to market networks. This is a somehow startling result, as social enterprises reported major gaps precisely in this type of knowledge.

Social enterprises, therefore, do not fully take advantage, not only through relationships built with other social enterprises but also with other external actors. More precisely, our analysis allowed us to classify social enterprises into three groups: (1) high knowledge actors - a restricted hard core of enterprises gaining all types of knowledge flows in both networks' typologies; (2) low knowledge 
actors - about one third of enterprises having little or no ability to gain knowledge in both networks' typologies; (3) substitute knowledge actors - a large part of enterprises considering the two reticular sources of knowledge as substitutes, thus taking advantage of only one typology of network.

In conclusion, our study's results confirmed that even though proximity, especially geographical, has encouraged the development of surprisingly cohesive interactions' networks, knowledge exchanges represent a marginal element, mainly restricted to a limited group able to take advantage from both sources of knowledge. By preventing social enterprises from developing their full potential and from innovating, overall, these findings are consistent with earlier empirical studies (see Giuliani and Bell, 2005; Morone et al., 2006; Giuliani 2007; Morrison and Rabellotti, 2009). Indeed, the Albanian civil society is still weak and the relationships between social enterprises, as clearly emerged in our analysis, are often still overseen by international donors. 


\section{References}

Ancori, B., Bureth, A., Cohendet, P. (2000) The Economics of Knowledge: The Debate About Codification and Tacit Knowledge. Industrial and Corporate Change 9(2), 255-287.

Anheier, H.K. and Ben-Ner, A. (2003) The Study of the Nonprofit Enterprise. Theories and Approaches. Kluwer Academic, New York.

Arrow, K. (1962) The Economic Implications of Learning by Doing. Review of Economic Studies 29, 155-173.

Audretsch, D. and Feldman, M.P. (1996) R\&D spillovers and the geography of innovation and production. American Economic Review 86 (3), 630-640.

Austin, J.E., Stevenson, H. and Wei-Skillern, J. (2006) Social Entrepreneurship and Commercial Entrepreneurship: Same, Different, or Both. Entrepreneurship Theory and Practice 30(1), 1-22.

Baptista, R. (2000) Do Innovations Diffuse Faster within Geographical Clusters? International Journal of Industrial Organization 18, 515-535.

Bathelt, H., Malmberg, A. and Maskell P. (2004) Clusters and Knowledge: Local Buzz, Global Pipelines and The Process of Knowledge Creation. Progress in Human Geography 28(1), 3156.

Birkhölzer, K. (2009) The role of social enterprise in local economic development. Paper given at the 2nd EMES Conference on Social Enterprise, Trent, Italy, July.

BIS (2011) A Guide to Legal Forms for Social Enterprise. Retrieved online at: https://www.gov.uk/government/uploads/system/uploads/attachment_data/file/31677/11-1400guide-legal-forms-for-social-enterprise.pdf

Bonatti, A., Begu, D., Sulka, K., Lahe, A. and Papadhima L. (2014) Social Enterprise, Social Innovation and Social Entrepreneurship in Albania: A National Report. EFESEIIS report Retrieved online at: http://www3.druid.dk/wp/20020012.pdf

Borgatti, S.P., Everett, M.G. and Freeman, L.C. (2002) Ucinet 6 for Windows: Software for Social Network Analysis. Analytic Technologies, Harvard, MA.

Borzaga, C. and Defourny, J. (2001) The Emergence of Social Enterprise. Routledge, London and New York.

Borzaga, C. and Tortia, E. (2009) Social Enterprises and Local Economic Development. In: The Changing Boundaries of Social Enterprises, OECD Publishing.

Boschma, R. (2005) Proximity and Innovation: A Critical Assessment. Regional Studies 39(1), 61 74.

Breschi, S. and Lissoni, F. (2003) Mobility and Social Networks: Localised Knowledge Spillovers Revisited. CESPRI Working paper 142. Retrieved online at: http://www.nber.org/CRIW/papers/breschi.pdf

Cornes, R. and Sandler, T. (1996) The Theory of Externalities, Public Goods, and Club Goods. Cambridge University Press, Cambridge MA.

Cowan, R., David, P.A. and Foray, D. (2000) The Explicit Economics of Knowledge Codification and Tacitness. Industrial and Corporate Change 9(2), 211-253.

Cowan, R. and Jonard, N. (2004) Network structure and the diffusion of knowledge. Journal of Economic Dynamics and Control 28(8), 1557-1575.

Crespo, J., Réquier-Desjardins, D. and Vicente, J. (2014) Why can collective action fail in local agri-food systems? A social network analysis of cheese producers in Aculco, Mexico. Food Policy 46, 165-177.

Cross, R., Parker, A. and Sasson, L. (2003) Networks in the Knowledge Economy. Oxford University Press, New York, pp.82-105. 
Dahl, M.S. and Pedersen, C.Ø.R. (2004) Knowledge flows through informal contacts in industrial clusters: myth or reality? Research Policy 33(10), 1673-1686.

Daniele, D., Johnson T. and Zandonai, F. (2009) Networks as Support Structures for Social Enterprises. In: The Changing Boundaries of Social Enterprises, OECD Publishing.

Datta, P.B. and Gailey, R. (2012) Empowering women through social entrepreneurship: Case study of a women's cooperative. Entrepreneurship Theory and Practice 36(3), 569-587.

Dávalos, E., Cancho, C. and Ceriani, L. (2015) An update on poverty and inequality in Albania: nine stylized facts. Washington, D.C. World Bank Group. Retrieved online at: http://documents.worldbank.org/curated/en/583911468187730890/An-update-on-poverty-andinequality-in-Albania-nine-stylized-facts

Davister, C., Defourny, J. and Grégoire, O. (2004) Work Integration Social Enterprises in the European Union: An Overview of Existing Models, Working Papers Series, no. 04/04, Liege: EMES European Research Network. Retrieved online at: http://orbi.ulg.be/bitstream/2268/90492/1/Work\%20Integration\%20Social\%20Enterprises\%20in \%20the\%20European\%20Union_An\%20overview\%20of\%20existing\%20models.pdf

Defourny, J. and Nyssens, M. (2008) Social enterprise in Europe: recent trends and developments. Social Enterprise Journal 4(3), 202-228.

Defourny, J. and Nyssens, M. (2010) Conceptions of Social Enterprise and Social Entrepreneurship in Europe and the United States: Convergences and Divergences. Journal of Social Entrepreneurship (1), 32-53.

Dershem, L., Dagargulia, T., Saganelidze, L. and Roels, S. (2011) NGO Network Analysis Handbook: how to measure and map linkages between NGOs. Save the Children. Tbilisi, Georgia. Retrieved on line at: http://www.dmeforpeace.org/sites/default/files/Dersham_NGO\%20Network\%20Analysis\%20Ha ndbook\%20Final.pdf

Dodgson, M. (1993) Organizational Learning: A Review of Some Literatures. Organization Studies 14(3), 375-394.

EMinS, SeConS (2014) Strategic Study on Social Economy Development in the Context of the South East Europe 2020 Strategy. Retrieved online at: http://www.europeanmovement.org.mk/wp-content/uploads/2014/08/FINAL-PDF-RCC_Studyon-SE-in-SEE-Region_FINAL.pdf

European Commission (2014) Albania Progress Report. Retrieved online at: http://ec.europa.eu/enlargement/pdf/key_documents/2014/20141008-albania-progressreport_en.pdf

Forsman, M. and Solitander, N. (2003), Knowledge Transfer in Clusters and Networks. Journal of International Business Studies - Literature Review 3, 1-23.

Gertler, M.S. (2003) Tacit knowledge and the economic geography of context, the undefinable tacitness of being (there). Journal of Economic Geography 3, 75-99.

Giuliani, E. (2007) The selective nature of knowledge networks in clusters: Evidence from the wine industry. Journal of Economic Geography 7(2), 139-168.

Giuliani, E. and Bell, M. (2005) The micro-determinants of meso-level learning and innovation: evidence from a Chilean wine cluster. Research Policy 34, 47-68.

Gorgoni, S. and Pietrobelli, C. (2010) Network structure, knowledge flows and innovation in the Chilean meat sector. International Journal of Business Environment 3(2), 159-178.

Grant, R.M. (1996) Toward a Knowledge-Based Theory of the Firm. Strategic Management Journal (Winter Special Issue) 17, 109-122.

Håkansson, H. (1989) Corporate Technological Behaviour: Co-operation and Networks. Routledge, London. 
Håkansson, H. and Snehota, I. (1995 ) Developing Relationships in Business Networks. Routledge, London.

Haldin-Herrgard, T. (2000) Difficulties in diffusion of tacit knowledge in organizations. Journal of Intellectual Capital 1(4), 357-365.

Hanneman, A. and Riddle, M. (2005) Introduction to social network methods. Riverside, CA: University of California, Riverside (published in digital form at http://faculty.ucr.edu/ hanneman/)

Haugh, H.M. and Talwar, A. (2014) Linking Social Entrepreneurship and Social Change: The Mediating Role of Empowerment. Journal of Business Ethics. Retrieved online at: http://link.springer.com/article/10.1007\%2Fs10551-014-2449-4\#page-1

Ingram, P. and Roberts, P.W. (2000) Friendship among Competitors in the Sydney Hotel Industry. American Journal of Sociology 106(2), 387-423.

Instat Albania (2013) Albania: trends in poverty 2002-2005-2008-2012. Retrieved online at: http://www.instat.gov.al/media/206685/living_standard_measurement_survey_2012_prelimin ary_results_.pdf

Jaffe, A.B., Trajtenberg, M. and Henderson, R. (1993) Geographical localization of knowledge spillovers as evidenced by patent citations. Quarterly Journal of Economics 108 (3), 577-598.

Katz, J.S. (1994) Geographical proximity and scientific collaboration. Scientometrics 31(1), 31-43.

Kerlin, J. (2006) Social Enterprise in the United States and Europe: Understanding and Learning from the Differences, Voluntas 17(3), 247-263.

Kimble, C. (2013) Knowledge management, codification and tacit knowledge. Information Research 18(2), 1-14.

Knoke, D. and Yang, S. (2008) Social network analysis. Sage Publications, Thousand Oaks.

Lissoni, F. (2001) Knowledge codification and the geography of innovation: the case of Brescia mechanical cluster. Research Policy 30(9), 1479-1500.

Lundvall, B.A. and Johnson, B. (1994) The learning economy. Journal of Industry Studies 1(2), 2342.

Maillat, D. (1998) From the Industrial District to the Innovative Milieu: Contribution to an Analysis of Territorised Productive Organisations. Recherches Economiques de Louvain 64(1), 111-129.

Marshall, A. (1920) Principles of Economics. Macmillan, London.

Maskell, P. and Malmberg, A. (1999) Localised Learning and Industrial Competitiveness. Cambridge Journal of Economics 23(2), 167-185.

Matei, L. and Matei, A. (2012) The social enterprise and the social entrepreneurship - instruments of local development. A comparative study for Romania. Procedia - Social and behavioral sciences 62, 1066-1071.

Matei, L. and Sandu, C. (2011) The social enterprise: a literature review, in Matei, A. and Radulescu, C. (Eds) (2011) National and European Values of public Administration in the Balkans. Ed. Economica, Bucaresti, pp.269-279.

Morone, P., Sisto, R. and Taylor, R. (2006) Knowledge diffusion and networking in the organic production sector: a case study. EuroChoices 5(3), 40-46.

Morone, P. and Taylor, R. (2010) Knowledge Diffusion and Innovation. Edward Elgar.

Morrison, A. and Rabellotti, R. (2009) Knowledge and information networks in an Italian wine cluster. European and Planning Studies 17(7), 983-1006.

Nonaka, I. (1991) The knowledge-creating company. Harvard Business Review 69(6), 96-104.

Nonaka, I. and Takeuchi, H. (1995) The Knowledge-Creating Company: How Japanese Companies Create the Dynamics of Innovation. Oxford University Press, New York. 
OECD/Eurostat (2005) Oslo Manual: Guidelines for Collecting and Interpreting Innovation Data, $3^{\text {rd }}$ Edition, The Measurement of Scientific and Technological Activities. OECD Publishing, Paris.

Oerlemens, L., Meeus, M. and Boekema F. (1998) Learning, innovation and proximity. The Netherlands Working Paper 98.3. Eindhoven Centre for Innovation Studies.

Patel, P. and Pavitt, K. (1991) Large Firms in the Production of the World's Technology: An Important Case of "Non-Globalisation". Journal of International Business Studies 22(1), 1-21.

Pinch, S., Henry, N., Jenkins, M. and Tallman, S. (2003) From 'industrial districts' to 'knowledge clusters': a model of knowledge dissemination and competitive advantage in industrial agglomerations. Journal of Economic Geography 3(4), 373-388.

Polanyi, M. (1966) The Tacit Dimension. Routledge, London

Porter, M.E. (1990) The Competitive Advantage of Nations. MacMillan, New York

Porter, M.E. (2000) Location, Competition, and Economic Development: Local Clusters in a Global Economy. Economic Development Quarterly 14(1), 15-35.

Powell, W. (1998) Learning from collaboration: Knowledge and networks in biotechnology and pharmaceutical industries. California Management Review 40(3), 228-240.

Quintane, E., Casselman, R.M., Reiche B. and Nylund, P.A. (2011) Innovation as a knowledgebased outcome, Journal of Knowledge Management 15(6), 928-947.

Rallet, A. and Torre, A. (2000) Is geographical proximity necessary in the innovation networks in the era of global economy? GeoJournal 49, 373-380.

Rosenberg, N. (1982) Inside the Black Box: Technology and Economics. Cambridge University Press, Cambridge.

Rykaszewski, S., Ma, M., and Shen, Y. (2013). Failure in Social Enterprises. SEE Change Magazine spring, 1-28. Retrieved online at: http://communitywealth.org/sites/clone.community-wealth.org/files/downloads/paper-rykaszewski-et-al.pdf

Saviotti, P.P. (2009) Knowledge networks: structure and dynamics. In: Pyka, A. and Scharnhorst, A. (Eds): Innovation Networks - New Approaches in Modelling and Analyzing. Springer, Berlin.

Saxenian, A.L. (1994) Regional Advantage: Culture and Competition in Silicon Valley and Route 128. Harvard University Press, Cambridge, MA.

Schrader, S. (1991) Informal technological transfer between firms: cooperation through information trading. Research Policy 20, 153-170.

Scott, J. (1991) Social network analysis: A handbook. Sage Publications.

Spear, R., et al. (2013) Boosting Social Entrepreneurship and Social Enterprise Creation in the Republic of Serbia. OECD Local Economic and Employment Development (LEED) Working Papers, No. 2013/12, OECD Publishing.

TACSO Project, ASE Forum (2013) Research Report Social Economy in Albania, A Survey on Social Enterprises. Retrieved online at: http://www.tacso.org/doc/TACSO\%20Albania\%20Office_Research\%20Report\%20on\%2

Torre, A. and Rallet, A. (2005) Proximity and Localization. Regional Studies 39(1), 47-59.

von Hippel, E. (1987) Cooperation between rivals: informal know-how trading. Research Policy 16(6), 291-302.

Wasserman, S. and Faust, K. (1994) Social Network Analysis, Methods and Applications. Cambridge University Press, Cambridge, MA.

Yunus, M. (2010) Building Social Business: The new kind of capitalism that serves humanity's most pressing needs. PublicAffairs.

Yunus, M., Moingeon, B. and Lehmann-Ortega, L. (2010) Building social business models: Lessons from the Grameen experience, Long Range Planning 43, 308-325. 